\title{
Cryoconite on a glacier on the north-eastern Tibetan plateau: light-absorbing impurities, albedo and enhanced melting
}

\author{
YANG LI, ${ }^{1,2,3}$ SHICHANG KANG,${ }^{3,4,5}$ FANGPING YAN, ${ }^{2}$ JIZU CHEN, ${ }^{4} \mathrm{KUN} \mathrm{WANG}^{4}$ \\ RUKUMESH PAUDYAL, ${ }^{4}$ JINGSHI LIU, ${ }^{1}$ XIANG QIN, ${ }^{4}$ MIKA SILLANPÄÄ ${ }^{2}$ \\ ${ }^{1}$ Key Laboratory of Tibetan Environment Changes and Land Surface Processes, Institute of Tibetan Plateau Research, \\ Chinese Academy of Sciences, Beijing 100101, China \\ ${ }^{2}$ Laboratory of Green Chemistry, Lappeenranta University of Technology, Mikkeli 50130, Finland \\ ${ }^{3}$ University of Chinese Academy of Sciences, Beijing 100049, China \\ ${ }^{4}$ State Key Laboratory of Cryospheric Science, Northwest Institute of Eco-Environment and Resources, Chinese Academy of \\ Sciences, Lanzhou 730000, China \\ ${ }^{5}$ CAS Center for Excellence in Tibetan Plateau Earth Sciences, Beijing 100085, China \\ Correspondence: Shichang Kang <shichang.kang@lzb.ac.cn>; Yang Li <liy@itpcas.ac.cn>
}

\begin{abstract}
Cryoconite is a dark-coloured granular sediment that contains biological and mineralogical components, and it plays a pivotal role in geochemistry, carbon cycling and glacier mass balance. In this work, we collected cryoconite samples from Laohugou Glacier No. 12 (LHG) on the north-eastern Tibetan Plateau during the summer of 2015 and measured the spectral albedo. To explore the impacts of this sediment on surface ablation, the ice melting differences between the cryoconite-free (removed) ice and the intact layers were compared. The results showed that the mean concentrations of black carbon (BC), organic carbon (OC) and total iron (Fe) in the LHG cryoconite were 1.28, 11.18 and $39.94 \mathrm{mg} \mathrm{g}^{-1}$, respectively. $\mathrm{BC}$ was found to play a stronger role in solar light adsorption than $O C$ and free Fe. In addition, ice covered by cryoconite exhibited the lowest mean reflectance (i.e., <0.1). Compared with the cryoconite-free ice surface, cryoconite effectively absorbed solar energy and enhanced glacial melting at a rate of $2.27-3.28 \mathrm{~cm} \mathrm{~d}^{-1}$, and free $\mathrm{Fe}, \mathrm{BC}$ and $\mathrm{OC}$ were estimated to contribute $1.01,0.99$ and $0.76 \mathrm{~cm} \mathrm{~d}^{-1}$, respectively. This study provides important insights for understanding the role of cryoconite in the glacier mass balance of the northern Tibetan Plateau.
\end{abstract}

KEYWORDS: black carbon, cryoconite, enhanced melting, spectral albedo, Tibetan plateau

\section{INTRODUCTION}

Cryoconite is a dark-coloured granular sediment found in supraglacial environments, and it represents an aggregate of mineral particles, black carbon (BC) and organic matter (OM) formed by microbial communities (Hodson and others, 2008; Stibal and others, 2012; Cook and others, 2016). This sediment originates from supraglacial and englacial entrainment, landslides from valley walls and aeolian processes through both natural and anthropogenic pathways (Mcintyre, 1984; MacDonell and Fitzsimons, 2008). Cryoconite significantly accelerates glacial melting by reducing the surface albedo and absorbing substantial solar radiation because of its dark colour (Takeuchi and others, 2015). Accordingly, cryoconite can often be found in small ice-lidded holes on the Antarctic ice sheet (Foreman and others, 2007), open holes or dispersed over the ablation surface of the Greenland ice sheet (Bøggild and others, 2010), European Alpine glaciers (Di Mauro and others, 2017) and Tibetan glaciers (Dong and others, 2016). Thus, it is important to study the roles of cryoconite in surface albedo reduction and ablation, particularly in areas where glaciers are experiencing rapid shrinking.

BC can strongly enhance absorption at visible and near-IR wavelengths (Dal Farra and others, 2018), whereas iron oxides, the primary light-absorbing component in mineral dust, reduce UV and visible reflectance (Lafon and others, 2006; Zhang and others, 2015). Therefore, BC and iron oxides have been regarded as the strongest light-absorbing impurities (LAIs) in the atmosphere and on ice and snow after deposition (Tegen and others, 1997; Sokolik and Toon, 1999; Hansen and Nazarenko, 2004; Flanner and others, 2007; Bond and others, 2013). Spatiotemporal variations in BC and dust (also Fe) have been observed, and their climatic implications have been assessed with respect to mountain glaciers (Qu and others, 2014; Kaspari and others, 2015; Li and others, 2017; Zhang and others, 2017a), ice sheets (Clarke and Noone, 1985; Doherty and others, 2010; Aoki and others, 2014) and seasonal snow (Painter and others, 2010; Huang and others, 2011; Doherty and others, 2014). However, studies reporting the concentrations of LAIs in cryoconite remain limited. In the Morteratsch Glacier (Swiss Alps), the concentrations of BC and $\mathrm{Fe}$ in cryoconite were $2.2-10$ and $27.7-50.5 \mathrm{mg} \mathrm{g}^{-1}$, respectively (Baccolo and others, 2017; Di Mauro and others, 2017). The Fe concentrations in cryoconite from a Himalayan glacier $\left(25.1 \pm 2.2 \mathrm{mg} \mathrm{g}^{-1}\right)$ were higher than those from Arctic glaciers (16.7-22.3 $\mathrm{mg} \mathrm{g}^{-1}$ ) (Singh and others, 2017), and the highest Fe concentration in cryoconite was reported for the Qiyi Glacier in the central Qilian Mountains (44.8-53.6 $\mathrm{mg} \mathrm{g}^{-1}$ ) (Wu and others, 2016). However, most studies have focused on the total mass per unit area or treated the OM in cryoconite as the only solar light absorber. The abundance of cryoconite on glacial ablation surfaces in the Arctic (Takeuchi and others, 2001a, 
2014) was found to be much lower than that on glaciers on the Tibetan Plateau and its surroundings, which is referred to as the Third Pole (Takeuchi and others, 2001b, 2005, 2006). The amount of OM contained in cryoconite represented $<3 \%$ of the total impurities in Antarctica (Foreman and others, 2007) and represented 5-10\% of the total impurities in the Third Pore (Takeuchi and others, 2001b, 2005, 2006; Takeuchi and Li, 2008), the subarctic (Takeuchi and others, 2001a; Stibal and others, 2006) and Greenland (Hodson and others, 2010; Takeuchi and others, 2014). Recently, Cong and others (2018) found that the OM in cryoconite was the most important light absorber at wavelengths of 450 and $600 \mathrm{~nm}$ and that goethite played a stronger role than BC at shorter wavelengths for most glaciers on the Tibetan Plateau. Moreover, it has been suggested that ice algae, especially during blooms, can darken the surface of the Greenland ice sheet (Yallop and others, 2012; Wang and others, 2018; Williamson and others, 2018). In addition, Ganey and others (2017) determined that microbial communities on the snow surface contributed to $17 \%$ of the total melting on an Alaskan icefield.

Compared with snow and ice surfaces, cryoconite typically exhibits stronger light absorption, and its broadband albedo is $<0.1$ due to its effective absorption of visible and near-IR wavelengths (Bøggild and others, 2010; Di Mauro and others, 2017). Thus, cryoconite can effectively influence the mass balance of glacier surfaces. In the ablation area of the Yala Glacier (Nepal Himalaya), dark-coloured cryoconite accelerated surface melting at a rate approximately threefold greater than that of impurity-free bare ice from which cryoconite material had been removed (Kohshima and others, 1993). In Russian Siberia, impurities increased the melting rate of ice surfaces by a factor of 1.6-2.6 with respect to clean bare ice without impurities (Takeuchi and others, 2015). However, studies on the impacts of LAls in cryoconite on albedo reduction and glacial melting in the Third Pole are still limited. Glaciers in this region could be greatly affected by the emissions of anthropogenic pollutants from East and South Asia (Kopacz and others, 2011).

This study aimed to describe the reduction in albedo and the enhancement of surface ablation by cryoconite in the western Qilian Mountains. In the present work, cryoconite samples were collected from Laohugou Glacier No. 12 (LHG) on the north-eastern Tibetan Plateau during the summer of 2015. The size distribution of incoherent granular cryoconite particles was measured (range 0.02-2000 $\mu \mathrm{m}$ ), and we evaluated the concentrations and light absorbability of $\mathrm{BC}$, organic carbon (OC) and $\mathrm{Fe}$ in cryoconite. Furthermore, the spectral and broadband albedos of both cryoconite and snow/ice surfaces were examined. A control experiment was carried out in the field to investigate the role of cryoconite in the acceleration of glacial melting.

\section{DATA AND METHODS}

\subsection{Study area}

LHG is the largest valley glacier in the western Qilian Mountains, and it is located on the north-eastern Tibetan Plateau $\quad\left(96^{\circ} 30^{\prime}-35^{\prime} \mathrm{E}, \quad 39^{\circ} 25^{\prime}-30^{\prime} \mathrm{N} ; \quad 4260-5481 \mathrm{~m}\right.$; Fig. 1a); faces northwest; covers an area of $20.4 \mathrm{~km}^{2}$; and is $\sim 9.85 \mathrm{~km}$ long (Du and others, 2008). The average equilibrium line altitude of LHG is $\sim 5015 \mathrm{~m}$ (Chen and others, 2017). The climate is typically arid and continental because it is controlled by the Siberian anticyclone and the westerly wind regime (Zhang and others, 2013). Since 1957, the terminals of LHG has retreated $240 \mathrm{~m}$ (Du and others, 2008), and the surface height has decreased by $18.6 \pm 5.4 \mathrm{~m}$, corresponding to a total volume loss of $0.218 \mathrm{~km}^{3}$ (Zhang and others, 2012). Over the same time period, the entire glacial area in the river basin has been reduced by $11.59 \%$ (Zhang and others, 2013) as a result of the increase in the annual mean temperature of $0.3^{\circ} \mathrm{C}$ per decade (Qin and others, 2015). Moreover, Sr-Nd isotopes and rare earth element geochemistry have indicated that dust in LHG primarily originates from the nearby Qaidam basin and the Tengger and Badain Jaran Deserts via longrange transport (Wei and others, 2017).

\subsection{Sample collection}

In the beginning of July 2015, cryoconite was commonly found in holes at a few centimetres deep and a few millimetres/centimetres wide. However, when we collected the samples, the cryoconite typically appeared as surface cryoconite and cryoconite basins and mounds. Surface cryoconite (i.e., dirty ice) is defined as a mixture of cryoconite granules and ice crystals on the glacier surface. Cryoconite basins are holes whose widths exceed their depths, and the floors of these basins are entirely covered by a combination of cryoconite material and water. Cryoconite mounds are composed of damp cryoconite materials that are concentrated and exposed on the glacier surface.

In total, 23 cryoconite samples from the ablation zone on LHG were collected with a stainless-steel shovel at elevations from 4350 to $4598 \mathrm{~m}$ on 25 July (nine samples, J1-J9) and 13 August 2015 (eight samples, A1-A8) and from 4598 to 4848 $\mathrm{m}$ on 16 August 2015 (six samples, A9-A14) (Fig. 1b). Sample sites of $25-400 \mathrm{~cm}^{2}$ area were established with an approximate elevation interval of $50 \mathrm{~m}$, typically on flat and homogeneous surfaces and along the centre line of LHG, and cryoconite was taken from the top 1-3 cm. The cryoconite samples were stored in Nalgene bottles $(250 \mathrm{ml}$, high-density polyethylene) and then transported to the State Key Laboratory of Cryospheric Science (Lanzhou) within a container filled with ice. All the samples were kept frozen until further analysis.

\subsection{Laboratory analysis}

\subsubsection{Grain size measurement}

The cryoconite samples were freeze-dried at $-70^{\circ} \mathrm{C}$ and then divided into six subsamples for measuring grain size, total $\mathrm{Fe}$, BC, total carbon (TC), inorganic carbon (IC, i.e., carbonate) and backup. The original subsamples for measuring grain size were weighed to $\sim 0.35 \mathrm{~g}$ using a microbalance (accuracy: $0.1 \mathrm{mg}$ ). The samples were then treated sequentially with $10 \mathrm{ml}$ of $30 \% \mathrm{H}_{2} \mathrm{O}_{2}$ (to remove $\mathrm{OM}$ ), $10 \mathrm{ml}$ of $1.5 \mathrm{M}$ $\mathrm{HCl}$ and $10 \mathrm{ml}$ of $1 \%$ sodium hexametaphosphate $\left[\left(\mathrm{NaPO}_{3}\right)_{6}\right]$ dispersant and sonicated for $90 \mathrm{~s}$ for dispersal (Feng and others, 2014). A Malvern Mastersizer 3000 was employed to examine the grain size distributions of the cryoconite samples.

\subsubsection{Analysis of total Fe}

Subsamples for the total Fe and carbonaceous matter analyses were ground into powder form (sieved in $75 \mu \mathrm{m}$ ). 

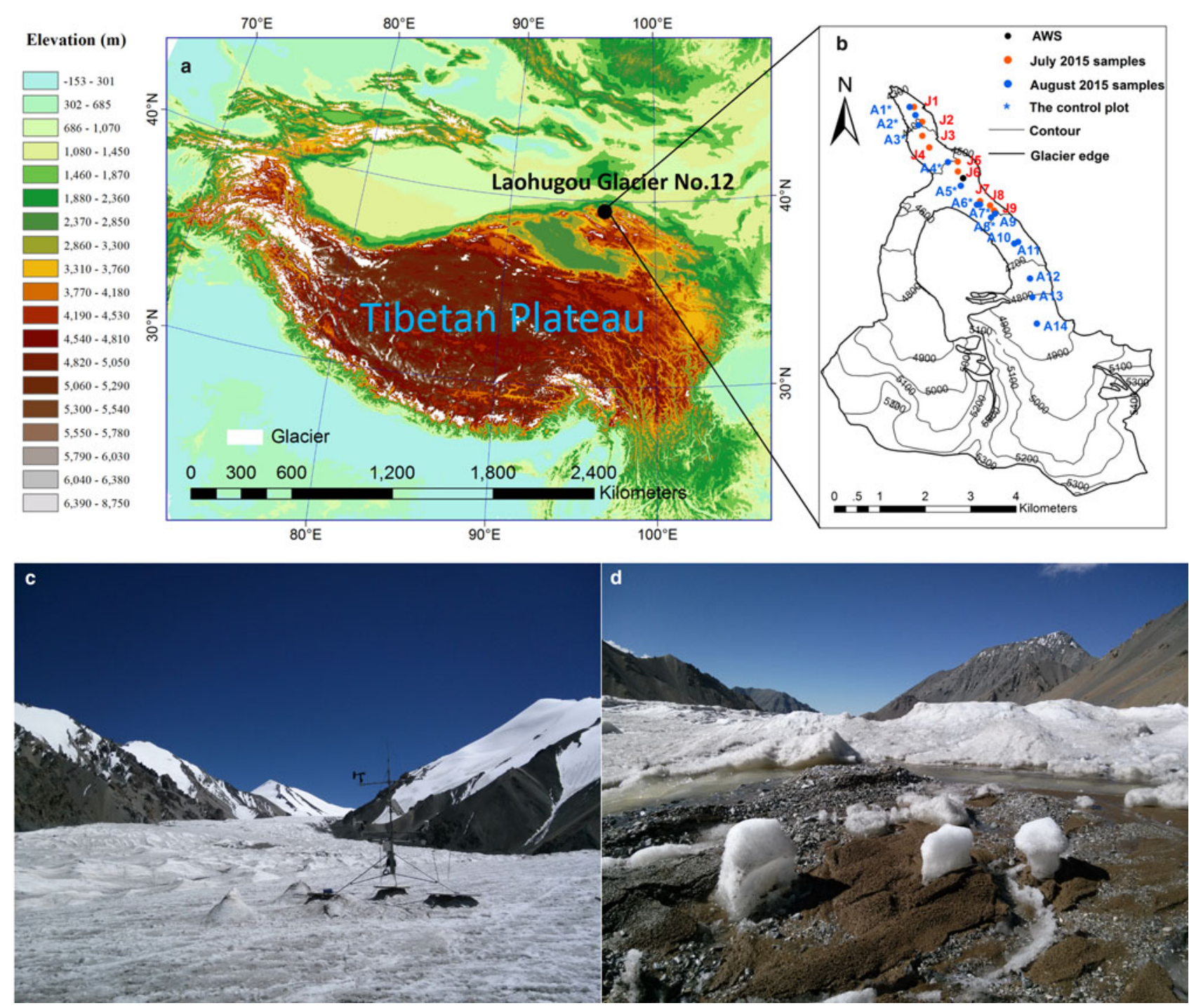

Fig. 1. (a) Topographic map (units: $m$ ) of LHG in the western Qilian Mountains, with (b) the sampling sites marked. The control experiments were implemented at A1-8. (c) Typical surface in the ablation zone of LHG and (d) glacier ice covered by debris and cryoconite at A8.

Subsamples ( 20 mg) for total Fe were dissolved via a pressurized acid digestion procedure following previously described methods (Liang and others, 2000). The abundances (by mass) of total Fe in the cryoconite was determined using inductively coupled plasma optical emission spectrometry (Teledyne Leeman Labs). A USGS geochemical reference standard (Andesite, AGV-2) was repeatedly measured to ascertain the accuracy and precision of the total Fe measurements. The measured values for total Fe agreed well with the standard (recovery of $>94 \%$ ). For each sample, total Fe was measured three times, and the relative std dev. were all $<10 \%$.

\subsubsection{Measurement of carbonaceous matter}

Elemental carbon (EC) is typically used as a proxy for BC because they are composed of the same fraction of carbonaceous particles (Lavanchy and others, 1999). In the present work, a procedure for separating BC from lake sediments was adapted for determining the $\mathrm{BC}$ in the cryoconite, and the detailed protocol can be found in previous papers (Han and others, 2011; Cong and others, 2013). Briefly, $\sim 0.1 \mathrm{~g}$ of the powder subsamples for BC was acid-treated $(\mathrm{HCl}$ and/or $\mathrm{HF})$ to avoid disturbances in the carbonates and other minerals, and the samples were then filtered via quartz fibre filters (Tissuquarz 2500QAO-UP, Pall, USA) that were $47 \mathrm{~mm}$ in diameter and presented an even distribution. The filters were analysed for BC using a thermal-optical carbon analyser (DRI 2015 model) according to the IMPROVE-A protocol, with the standard OC-EC split at $635 \mathrm{~nm}$ (Chow and others, 2007), and we used varieties of the thermal-optical reflectance (TOR) and transmittance (TOT) signals to determine the $\mathrm{BC}_{\mathrm{TOR}}$ and $\mathrm{BC}_{\mathrm{TOT}}$, respectively. Moreover, three blanks were prepared and analysed following the same procedure as the samples, although no BC was detected. TC and IC were analysed using a TOC$\mathrm{V}_{\mathrm{CPH}}$ carbon analyser (Shimadzu Corp., Japan), and the results were calculated as mass percentages. Thus, $\mathrm{OC}=$ $\mathrm{TC}-\mathrm{IC}-\mathrm{BC}$ (the average of $\mathrm{BC}_{\mathrm{TOR}}$ and $\mathrm{BC}_{\mathrm{TOT}}$ ).

\subsection{Measurement of spectral albedo}

The reflectance measurements of cryoconite/snow/ice surface were carried out with an Analytical Spectral Devices FieldSpec 3 (ASD ${ }^{\circledR}$ FS-3) spectroradiometer (radiation wavelengths: $350-2500 \mathrm{~nm}$ ) during the field survey in 2015. To cover the sample surface, the sensor $\left(25^{\circ}\right.$ collimating lens) was held at an $\sim 0.5 \mathrm{~m}$ height (footprint: $386 \mathrm{~cm}^{2}$ ) directly above the sample surface. A nearly perfect 
Lambertian reflector was used as a white reference surface, which was measured before and after each new measurement (Cook and others, 2017). At each site, the spectral albedos were measured ten times and averaged within 5 min, with the assumption that the effect of atmospheric and illuminative conditions cannot be altered (Negi and Kokhanovsky, 2011).

To minimize disturbances from significant stray light at shorter wavelengths, we calculated only the broadband albedos at radiation wavelengths from 500 to $2500 \mathrm{~nm}$ via a standard terrestrial solar spectral irradiance distribution, which was provided by the American Society for Testing and Materials (ASTM G-173-03 data). The broadband albedo $\left(\alpha_{\text {broad }}\right)$ was calculated by Eqn (1):

$$
\alpha_{\text {broad }}=\frac{\int_{500}^{2500} \alpha_{\text {narrow }}(\lambda) i(\lambda) \mathrm{d} \lambda}{\int_{500}^{2500} i(\lambda) \mathrm{d} \lambda}
$$

where $\alpha_{\text {narrow }}(\lambda)$ and $i(\lambda)$ denote the measured narrowband albedo and incoming solar irradiance reference at wavelength $\lambda$, respectively (Ming and others, 2013).

\subsection{Calculation of Incident Radiative Forcing}

In terms of the broadband albedo $\left(\alpha_{\text {broad }}\right)$ and broadband albedo reduction caused by LAls ( $A R_{x}^{b r o a d}$ ), the Incident Radiative Forcing (IRF) absorbed by the glacier surface and LAls can be obtained using Eqn (2):

$$
\mathrm{IRF}_{x}=R_{\mathrm{in}-\text { short }} \times\left(1-\alpha_{x}^{\text {broad }}\right)=R_{\mathrm{in}-\text { short }} \times \mathrm{AR}_{x}^{\text {broad }}
$$

where $R_{\text {in-short }}$ indicates the incident incoming shortwave solar radiation measured by Kipp and Zonen Net Radiation
LITE radiometers (300-2800 $\mathrm{nm}$ ), which were set up at a height of $1.5 \mathrm{~m}$ in the ablation zone of LHG $\left(39.478^{\circ} \mathrm{N}\right.$, $\left.96.535^{\circ} \mathrm{E} ; 4550 \mathrm{~m}\right)$. Radiation data for the study period are presented in Fig. S1.

\subsection{Control experiment}

To assess the effect of cryoconite on surface ablation, a control experiment was implemented in the field. The cryoconite material on the glacier surface ice (covering an area of at least $30 \times 30 \mathrm{~cm})$ was removed from A1-A8 $(11$ sites, two sites at A1, A6 and A8) in the LHG ablation zone on 13 August 2015 (Fig. 1b). First, the majority of cryoconite material was removed with a sterile stainless-steel shovel, and then we washed the surface ice by water to clean the residual cryoconite. The spectral albedos and changes in surface conditions were measured, and comparisons were conducted between the experimental plots (cryoconite-free glacier ice) and the control plots with intact cryoconite layers from 13 to 25 August 2015.

\section{RESULTS AND DISCUSSION}

\subsection{Particle size distribution}

The grain size distributions of the cryoconite particles clearly illustrated that cryoconite was primarily composed of silt grains $(\sim 2-63 \mu \mathrm{m})$, which accounted for $81.9-89.7 \%$ of the total cryoconite (Fig. 2). The mean clay grain $(<2 \mu \mathrm{m})$ content ranged from 4.6 to $8.0 \%$. The mean sand $(>63 \mu \mathrm{m})$ content ranged from 3.2 to $12.4 \%$, with an average of $8.1 \%$. In addition, the grain size distribution showed a unimodal pattern with a modal size of $9.8-14.5 \mu \mathrm{m}$, which is
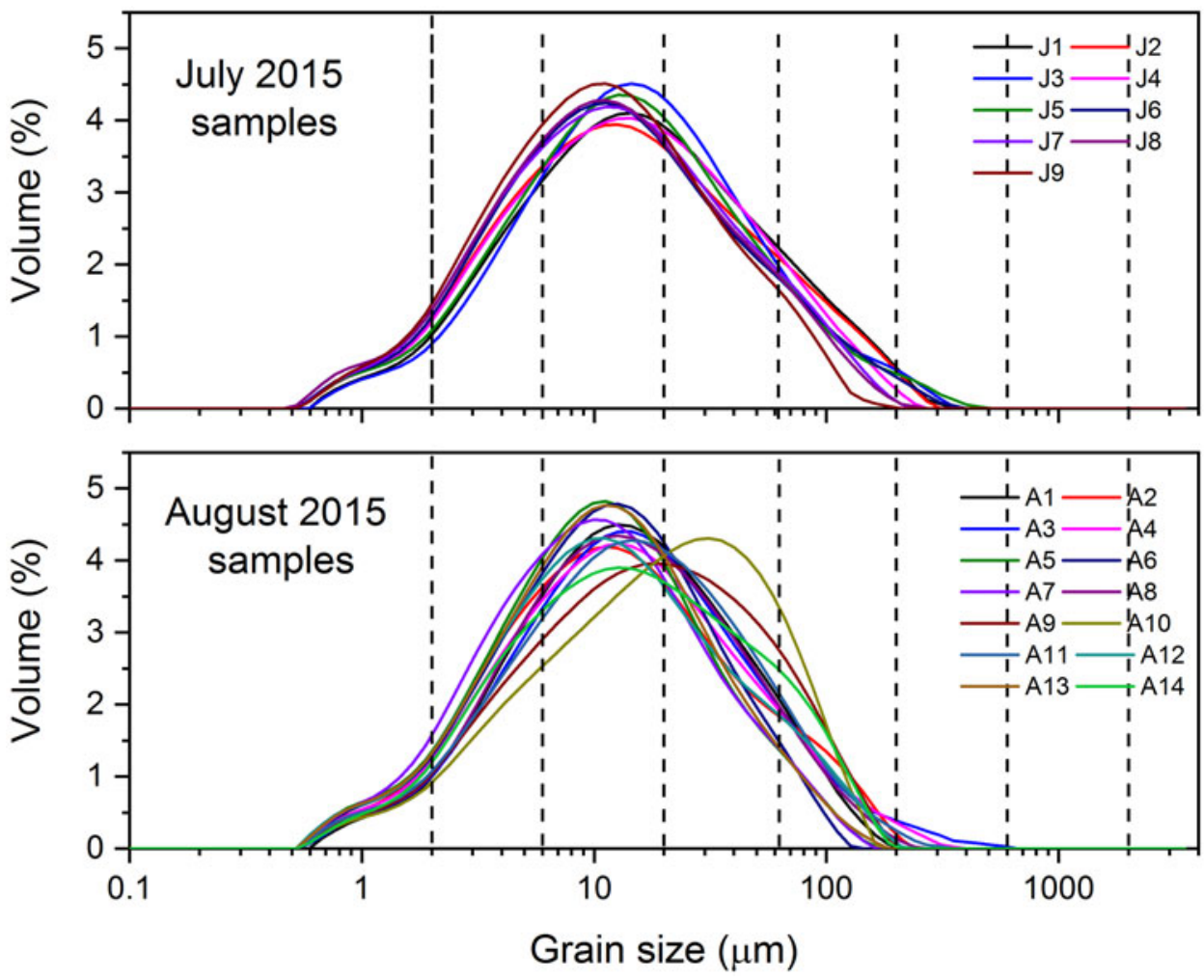

Fig. 2. Grain size distributions of cryoconite particles measured during the two expeditions shown in Figure 1. The size categories are as follows: clay (diameter $<2 \mu \mathrm{m})$, fine silt $(2-6 \mathrm{~mm})$, medium silt $(6-20 \mu \mathrm{m})$, coarse silt $(20-63 \mu \mathrm{m})$, fine sand $(63-200 \mu \mathrm{m})$, medium sand $(200-600 \mu \mathrm{m})$ and coarse sand $(600-2000 \mu \mathrm{m})$. 
similar to that described in previous deposition studies on LHG cryoconite (Dong and others, 2016), melting water (Dong and others, 2014a) and snow pits (Dong and others, $2014 b$ ), larger than that in aerosol samples (Xu and others, 2013) but smaller than that in surface soils from potential sources (Zhang and others, 2016).

\subsection{Concentrations and light absorption of Fe and carbonaceous matter in cryoconite}

In this study, the total Fe concentrations ranged from 15.46 to $51.92 \mathrm{mg} \mathrm{g}^{-1}$, with a mean value of $39.94 \mathrm{mg} \mathrm{g}^{-1}$ (Fig. 3a), which is similar to the observed total Fe concentrations in cryoconite from LHG (Cong and others, 2018), aerosols from Dunhuang (180 km away from LHG) (Zhang and others, 2003) and samples of the upper continental crust. Similar levels of total Fe in cryoconite have also been reported in previous studies on Qiyi Glacier in the central Qilian Mountains (Wu and others, 2016), Urumqi No. 1 Glacier in the Tienshan Mountains, Baishui No. 1 Glacier in the Yulong Mountains (Cong and others, 2018) and Morteratsch Glacier in the Swiss Alps (Baccolo and others, 2017). The aforementioned total Fe concentrations were much higher than those recorded at glaciers in the Himalaya and Arctic (Singh and others, 2013, 2017) (Table 1).

$\mathrm{BC}$ is primarily obtained from the incomplete combustion of biomass and fossil fuels, and it is considered to be the second largest warming agent after $\mathrm{CO}_{2}$ (Bond and Bergstrom, 2006; Ramanathan and Carmichael, 2008). East Asia and South Asia are the largest emitters of BC (Lu and others, 2012), which can be transported to the Tibetan Plateau (Luthi and others, 2015). Therefore, BC in the Tibetan Plateau has become an important research topic in recent years. In general, the concentrations of $\mathrm{BC}_{\mathrm{TOR}}$ in the LHG cryoconite $\left(0.59-1.74 \mathrm{mg} \mathrm{g}^{-1}\right)$ were $\sim 5 \%$ more than the concentrations of $\mathrm{BC}_{\text {TOT }}\left(0.61-1.69 \mathrm{mg} \mathrm{g}^{-1}\right)$ shown in Fig. S2, which is consistent with the results of a previous study (Chen and others, 2015), and this phenomenon is related to the recovery of the initial transmittance signal value after a delay. In this study, the $\mathrm{BC}$ concentration was based on the average concentrations of $\mathrm{BC}_{\mathrm{TOR}}$ and $\mathrm{BC}_{\mathrm{TOT}}$ at each sampling site, and it averaged $1.28 \pm 0.25 \mathrm{mg} \mathrm{g}^{-1}$ (Fig. 3a). Our data are consistent with previously reported BC concentrations in cryoconite across the Third Pole but lower than those reported for Baishui No. 1 Glacier in the Yulong Mountains (Cong and others, 2018) and Morteratsch Glacier in the Swiss Alps (Baccolo and others, 2017) (Table 1). The higher values in the latter regions are indicative of greater anthropogenic influence. Baishui No. 1 Glacier is typically affected by anthropogenic BC transported from South Asia and East Asia (the largest BC emitters) via the Indian summer monsoon and East Asian summer monsoon (Niu and others, 2018), and Morteratsch Glacier is located within tens of kilometres from the most industrialized and inhabited region of Europe, the Po Valley. BC sources to LHG, however, are separated by several hundred kilometres (e.g., Hexi Corridor) or thousand kilometres (e.g., eastern China).

Furthermore, $\mathrm{BC}$ can be divided into char (BC measured at low temperature $\left(580^{\circ} \mathrm{C}\right)$ minus the pyrolysed carbon, $\left.\mathrm{BC}_{\mathrm{LT}}\right)$ and soot (the sum of $\mathrm{BC}$ measured at high temperatures (740 and $\left.840^{\circ} \mathrm{C}\right), \mathrm{BC}_{\mathrm{HT}}$ ) based on the IMPROVE-A protocol. The ratio of $\mathrm{BC}_{\mathrm{LT}}$ to $\mathrm{BC}_{\mathrm{HT}}$ can be used to identify the source (Han and others, 2007; Cong and others, 2013). In the
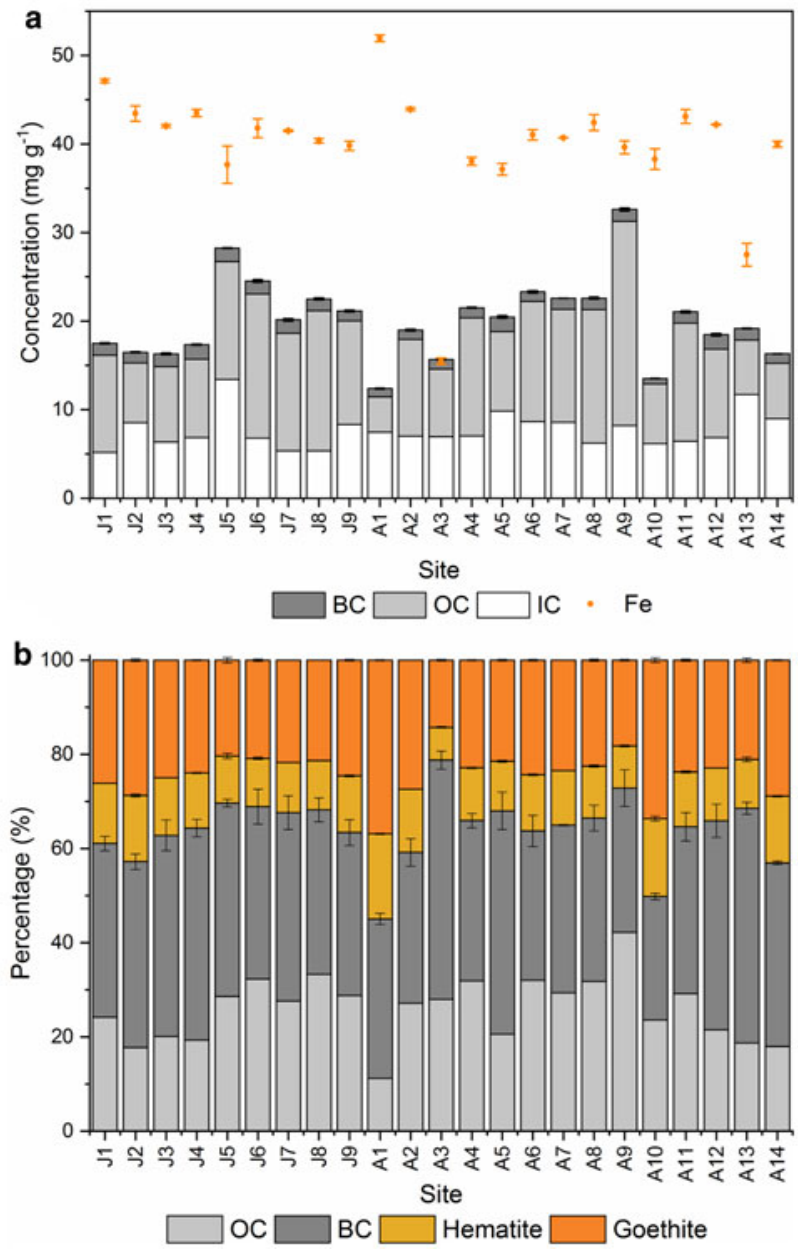

Fig. 3. (a) Concentrations of total Fe and carbonaceous matter in cryoconite collected on the surface of LHG during the summer of 2015. (b) Proportions of total light absorption contributed by OC, $\mathrm{BC}$, hematite and goethite. Error bars indicate the std dev..

LHG cryoconite, the values of $\mathrm{BC}_{\mathrm{LT}-\mathrm{TOR}} / \mathrm{BC}_{\mathrm{HT}-\mathrm{TOR}}$ and

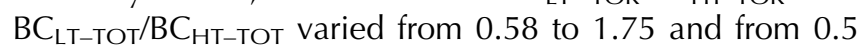
to 1.82 , respectively (Fig. 4), indicating that fossil fuel contributed the majority of $\mathrm{BC}$ in the LHG cryoconite. This finding is compatible with the recent source-diagnostic $\Delta^{14} \mathrm{C} / \delta^{13} \mathrm{C}$ compositions of BC isolated from LHG snow pit, which revealed that fossil fuels contribute $66 \pm 16 \%$ (Li and others, 2016).

In this study, TC was divided into IC, OC and $\mathrm{BC}$. TC concentrations in the LHG cryoconite ranged between 12.36 and $32.49 \mathrm{mg} \mathrm{g}^{-1}$ and averaged $20.09 \mathrm{mg} \mathrm{g}^{-1}$. Although the average concentrations of IC, OC and total Fe (7.67, 11.18 and $39.94 \mathrm{mg} \mathrm{g}^{-1}$, respectively) were much higher than those of BC (Fig. 3a), the light absorbability of IC is typically trivial and thus ignored, whereas $\mathrm{BC}$ is a much more effective absorber than $\mathrm{OC}$ and Fe. Accordingly, the mass absorption cross-section (MAC) values for uncoated BC and OC particles are 7.5 and $0.6 \mathrm{~m}^{2} \mathrm{~g}^{-1}(550 \mathrm{~nm})$, respectively (Kirchstetter and others, 2004; Bond and Bergstrom, 2006). In this study, we referenced the average ratios of goethite/ total Fe and hematite/total Fe (0.486 and 0.065, respectively) in the LHG cryoconite (Cong and others, 2018) to calculate the concentrations of goethite and hematite to effectively control for the absorption of dust. In addition, the MAC values for the goethite (Stream Chemicals, Inc., Newburyport, MA, USA) and hematite standards (Sigma 
Table 1. Comparisons of the total Fe and BC concentrations in cryoconite samples from the Third Pole, European Alps and Arctic glaciers

\begin{tabular}{|c|c|c|c|c|c|}
\hline Region & Area & Glacier & Total Fe concentration $\left(\mathrm{mg} \mathrm{g}^{-1}\right)$ & BC concentration $\left(\mathrm{mg} \mathrm{g}^{-1}\right)$ & Source \\
\hline \multirow[t]{7}{*}{ Third Pole } & Tienshan & Urumgi No. 1 & $46.2 \pm 2.2$ & $0.98 \pm 0.09$ & Cong and others. (2018) \\
\hline & Qilian & Laohugou No. 12 & $39.94 \pm 6.88$ & $1.28 \pm 0.25^{\mathrm{a}}$ & This work \\
\hline & & & $42.8 \pm 1.7$ & $1.05 \pm 0.18$ & Cong and others. (2018) \\
\hline & & Qiyi & $44.8-53.6$ & & Wu and others. (2016) \\
\hline & Tanggula & Xiaodongkemadi & $34.8 \pm 1.8$ & $0.65 \pm 0.06$ & Cong and others. (2018) \\
\hline & Southeast TP & Palong No. 4 & $41.8 \pm 1.3$ & $1.29 \pm 0.35$ & Cong and others. (2018) \\
\hline & Himalaya & Sutri Dhaka & $25.12 \pm 2.18$ & & Singh and others. (2017) \\
\hline European Alps & Swiss Alps & Morteratsch & $40.85 \pm 6.55$ & $2.2-10$ & $\begin{array}{l}\text { Baccolo and others. (2017); } \\
\text { Di Mauro and others. (2017). }\end{array}$ \\
\hline \multirow[t]{3}{*}{ Arctic } & Svalbard & Austre Brøggerbreen & $22.34 \pm 1.47$ & & Singh and others. (2017) \\
\hline & & Vestre Brøggerbreen & $16.71 \pm 0.99$ & & Singh and others. (2017) \\
\hline & & Midre Lovénbreen & $28.17-32.41$ & & Singh and others. (2013) \\
\hline
\end{tabular}

a Average values of $\mathrm{BC}_{\mathrm{TOR}}$ and $\mathrm{BC}_{\mathrm{TOT}}$

Aldrich Inc., St. Louis, MO, USA) at $550 \mathrm{~nm}$ were set, respectively, at 0.31 and $1.13 \mathrm{~m}^{2} \mathrm{~g}^{-1}$ (Cong and others, 2018). Here, we assumed that the light absorption of LAls $=$ concentrations $_{\text {LAls }} \times M_{\text {AACls }}$ and components other than BC, OC and free Fe in the LHG cryoconite could be considered negligible with respect to solar light adsorption. Putting together these pieces of information about LAIs concentration and properties, we conclude that the BC in the LHG cryoconite was responsible for a higher fraction of light absorption $(38.1 \%)$ than the Fe (goethite + hematite, $35.9 \%$ ) and OC (26.0\%) at $550 \mathrm{~nm}$ (Fig. 3b). Recently, Cong and others (2018) found that BC in LHG cryoconite also contributed more to light absorption than free Fe at $600 \mathrm{~nm}$, whereas goethite played a stronger role at short wavelengths due to its higher MAC value $\left(1.55 \pm 0.08 \mathrm{~m}^{2} \mathrm{~g}^{-1}\right.$ at $450 \mathrm{~nm}$, $0.15 \pm 0.01 \mathrm{~m}^{2} \mathrm{~g}^{-1}$ at $\left.600 \mathrm{~nm}\right)$. Furthermore, in their study, OM dominated light absorption at both 450 and $600 \mathrm{~nm}$ because OM is composed of LAls other than OC, such as soil humus, humic-like substances and microbial particles. However, only OC was considered in our study.

\subsection{Spectral and broadband albedos}

In addition to the angular and spectral distribution of incoming solar radiation, snow albedo is influenced by the physical properties of the snow (e.g., complex refractive index, optically equivalent grain size, density, depth, liquid water content and LAls within the snowpack) (Warren and Wiscombe, 1980; Wiscombe and Warren, 1980). The spectral and broadband albedos for various types of LHG surfaces measured in the field are shown in Figure 5 and Table 2, respectively. The rough shape of the snow spectral albedo is controlled by the complex refractive index of ice, which is very close to that of liquid water for $\lambda<5 \mu \mathrm{m}$ (Warren and Wiscombe, 1980). Therefore, the valleys at wavelengths of 770-830, 870-920, 1000-1060, 1200-1300, 1400$1600,1900-2100$ and $2400-2500 \mathrm{~nm}$ were attributed to the peak values of light absorption of ice/water at the corresponding wavelengths (Warren and Brandt, 2008).

The cryoconite basin and mound as well as the moraine sediments had the lowest spectral albedos in Figure $5 \mathrm{a}$, and the mean values were $<0.1$ across the visible and near-IR region. In general, the spectral albedos increased at wavelengths shorter than $560 \mathrm{~nm}$ and decreased at wavelengths longer than $2300 \mathrm{~nm}$. In particular, the cryoconite mound, that is substantially dry, and moraine and moraine sediments (3 and 10 in Fig. 5, respectively) showed higher reflectance than the wet cryoconite accumulated in ice holes or dispersed on the glacier surface (6 and 12 in Fig. 5). The reason for this is linked to the effect played by wetness and liquid water on light absorption; it is commonly known that the presence of superficial liquid films decreases

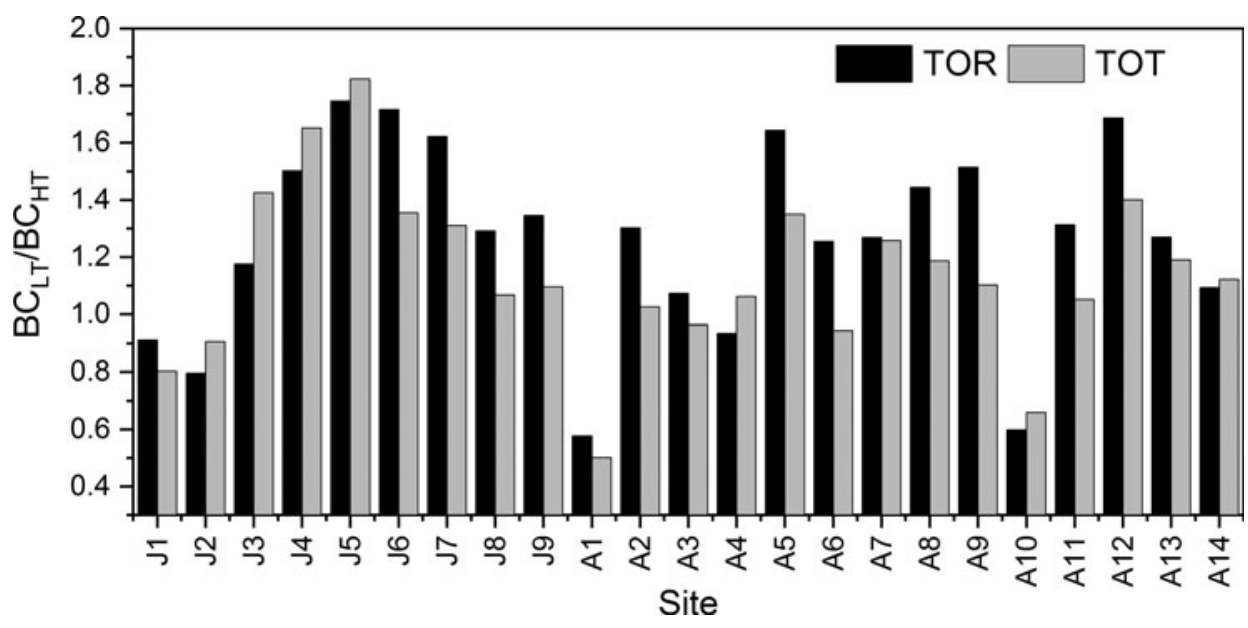

Fig. 4. Ratios of BCLT to BCHT in cryoconite collected on the surface of LHG during the summer of 2015. (TOR and TOT represent the thermal-optical reflectance and transmittance method, respectively.) 

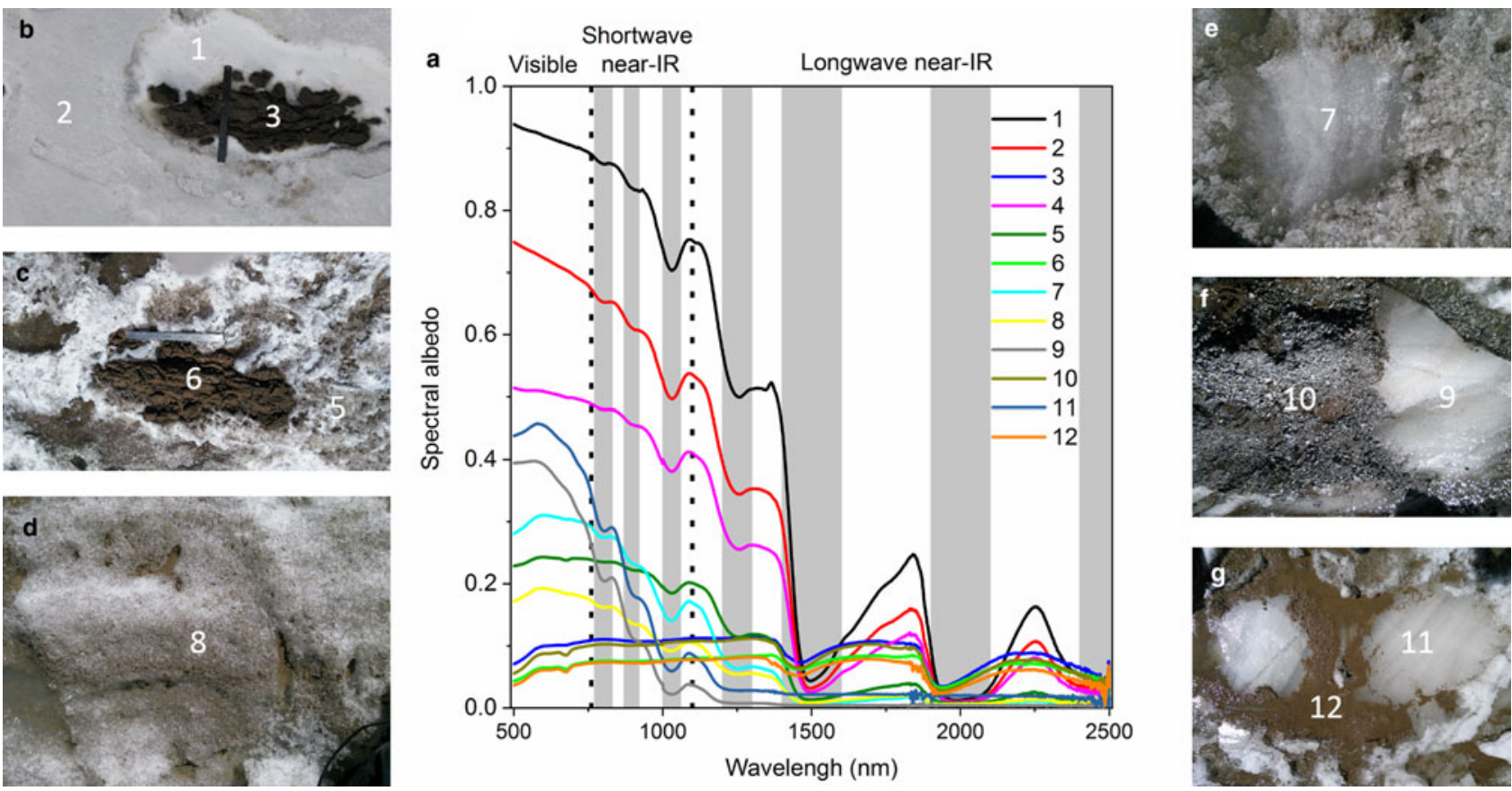

Fig. 5. (a) Spectral albedos of cryoconite/snow/ice in the ablation zone (greyed shading for known water absorption wavelengths). Broadband albedos for the cryoconite/snow/ice types listed in Table 2. (b) Snow surrounding the cryoconite ice mound (A14 in Table 2); (c) ice surrounding the cryoconite ice mound (A12 in Table 2); (d) and (e) surface ice and cryoconite materials, respectively (A1-2 in Table 2); (f) surface ice before and after the removal of uniform debris (A9 in Table 2); and (g) cryoconite basin (A7 in Table 2).

the albedo of some materials (Ångström, 1925; Lekner and Dorf, 1988), including cryoconite (Di Mauro and others, 2017). Once the cryoconite material and moraine sediments were removed, the spectral albedos of the cryoconite/ moraine-free ice (9 and 11 in Fig. 5) increased in the visible light and shortwave NIR range but decreased in the longwave NIR wavelengths and even approached zero at wavelengths longer than $1500 \mathrm{~nm}$, indicating that the glacier ice contained less LAIs and that much of the NIR radiation was absorbed by the melting ice surface and/or transmitted into deeper layers. These effects complemented each other, resulting in higher broadband albedos for clean ice layers.

The shape of the spectral albedos for surface snow (1, 2 and 4 in Fig. 5) and ice (3 and 5 in Fig. 5) near the cryoconite mound was generally similar to those for snow and sea ice measured in the Arctic (Bøggild and others, 2010; Aoki and others, 2013; Pope and Rees, 2014). The reflectance of snow showed a higher average range across almost all the investigated spectra than those of other types of surfaces.

Table 2. Broadband solar albedos for characteristic snow/ice/cryoconite types in LHG (August 2015). (1) Cryoconite basin, (2) cryoconite mound, (3) surface ice with cryoconite, (4) surface ice after the removal of cryoconite, (5) surface ice with uniform debris, (6) surface ice after the removal of debris, (7) coarse-grained ice around the cryoconite mound, (8) coarse-grained snow around the cryoconite ice mound, (9) cloud amount, (10) solar zenith angle and (11) elevation (m)

\begin{tabular}{|c|c|c|c|c|c|c|c|c|c|c|c|}
\hline Site & 1 & 2 & 3 & 4 & 5 & 6 & 7 & 8 & 9 & 10 & 11 \\
\hline A $1-1$ & 0.10 & & & 0.19 & & & & & 0 & 45.1 & 4350 \\
\hline A1-2 & & & 0.13 & 0.21 & & & & & 0 & 42.4 & 4349 \\
\hline A2 & 0.12 & & & 0.15 & & & & & 0 & 38.7 & 4375 \\
\hline A3-1 & 0.09 & & & 0.18 & & & & & 0 & 30.4 & 4402 \\
\hline A3-2 & & & 0.14 & 0.24 & & & & & 0 & 28.3 & 4402 \\
\hline A4 & & 0.11 & & 0.49 & & & & & 0 & 25.4 & 4501 \\
\hline A5 & 0.11 & & & 0.29 & & & & & 1 & 24.7 & 4552 \\
\hline A6-1 & 0.09 & & & 0.22 & & & & & 2 & 25.1 & 4577 \\
\hline A6-2 & & & 0.22 & 0.52 & & & & & 2 & 26.1 & 4577 \\
\hline A7 & 0.09 & & & 0.20 & & & & & 1 & 36.3 & 4575 \\
\hline A8-1 & & & 0.10 & 0.25 & & & & & 1 & 44.5 & 4598 \\
\hline A8-2 & & & & & 0.07 & 0.26 & & & 1 & 51.7 & 4598 \\
\hline A9 & & 0.05 & & & & & $0.21-0.33$ & & 2 & 46 & 4598 \\
\hline A10 & & 0.10 & & & & & 0.22 & & 3 & 38.1 & 4688 \\
\hline A11 & & 0.10 & & & & & 0.30 & & 3 & 38.1 & 4688 \\
\hline A12 & & 0.07 & & & & & $0.19-0.40$ & & 3 & 36.3 & 4742 \\
\hline A13 & & 0.09 & & & & & & $0.58-0.77$ & 7 & 30.2 & 4806 \\
\hline A14 & & 0.10 & & & & & & $0.56-0.74$ & 8 & 27.3 & 4848 \\
\hline
\end{tabular}


The dirty ice albedos showed low reflectance values of $\sim 0.3$ in the visible wavelengths and $<0.2$ in the NIR wavelengths due to the presence of LAls, which dramatically altered the optical properties of these surfaces. In this work, we did not measure the concentrations of LAls in surface snow/ice, although the concentrations of $\mathrm{BC}$ and mineral dust in LHG snow pits have been reported to be only $35 \mathrm{ng} \mathrm{g}^{-1}$ (Ming and others, 2009) and $3.5 \mathrm{\mu g} \mathrm{g}^{-1}$ (Dong and others, $2014 b)$, respectively, whereas BC concentrations of up to $2000 \mathrm{ng} \mathrm{g}^{-1}$ have been observed in surface snow/ice (Zhang and others, 2017c). The lower LAI concentrations could explain the higher broadband albedos of the coarsegrained snow (0.56-0.77) and ice (0.19-0.4) surrounding the cryoconite. After spreading to nearly clean snow/ice surfaces via wind, streams or gravity, cryoconite granules containing abundant LAIs reduce the surface albedo, efficiently absorb solar radiation, accelerate glacial melting and produce holes in the ice.

\subsection{Surface melting caused by cryoconite}

The changes between the control and experimental plots during the study period were recorded at eight different elevations in the ablation zone (Fig. 6 and Table 3). After a few hours of melting, the ice surfaces at the experimental plots became whiter and $\sim 1-2 \mathrm{~cm}$ higher than their surroundings (i.e., the control plots in Fig. 6a) on 13 August 2015. The low-density and more opaque layer formed in the uppermost glacier ice was referred to as weathering crust (Müller and Keeler, 1969). Although the weathering crust contained LAIs and would be reduced by net radiation and sensible heat, it could result in a greater reflection of incident radiation than absorption by the melting ice surface and/or greater transmittance to deeper layers. Therefore, the melting rate of the subsurface ice layer was confined (Irvine-Fynn and Edwards, 2014). However, the dirty cryoconite layers in the control plots were merely a few millimetres thick; therefore, the heat fluxes could be transported to the subsurface ice layer, thereby increasing the temperature of the subsurface ice layer to $0^{\circ} \mathrm{C}$ and accelerating melting.

After the $12 \mathrm{~d}$ in situ experiment, the ice pillars that survived in the experimental plots were $28-40 \mathrm{~cm}$ higher than the control plots' surfaces. The ice pillars were covered by a layer of porous ice with loosely interlocking crystals underlain by material with a higher density. Therefore, the cryoconite material increased glacial melting by a factor of 2.27$3.28 \mathrm{~cm} \mathrm{~d}^{-1}$ relative to cryoconite-free ice surfaces under the same meteorological conditions (Fig. S1). For comparison, cryoconite accelerated surface ablation at a rate $\sim$ three and 1.6-2.6 times greater than that observed for cryoconite-free bare ice in Yala Glacier (Nepal Himalaya) (Kohshima and others, 1993) and in Glacier No. 31 (Russian Siberia) (Takeuchi and others, 2015), respectively. Additionally, there was a poor correlation $\left(R^{2}<0.1\right)$ between the enhanced melting rate and the broadband albedos of the control plots (Fig. S3a). Furthermore, there was no obvious altitude effect on the melting rate $\left(R^{2}<\right.$ 0.22 ) (Fig. S3b), indicating that the results could be also influenced by these unmeasured factors, such as the liquid water content and thickness of the cryoconite, which could impact the transmitting efficiency of conductive heat, slope and aspect, which could in turn influence the abundance of solar radiation reaching the glacial surface.

\subsection{Estimated albedo reduction and surface ablation by LAls in cryoconite}

Because the spectral albedos of the weathering crust were not measured in the field, we simulated them using the SNICAR-online model (Flanner and others, 2007), which is constrained by the average concentrations of $\mathrm{BC}$ and dust

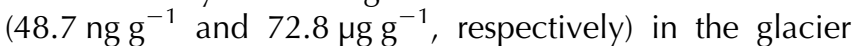
ice layers (excluding the dirty layers) of an ice pit excavated in the ablation area (4550 m) of LHG (1 August 2016). We used a snow optical grain radius of $1500 \mu \mathrm{m}$ and a snow density of $600 \mathrm{~kg} \mathrm{~m}^{-3}$. Atmospheric conditions were input as a clear or cloudy sky based on the observed incoming shortwave radiation. Snow thickness was assumed to be 1 $\mathrm{m}$. Albedos of the underlying ground followed the recommended values for the SNICAR model (visible: 0.2, near-IR: 0.4). The simulated spectral albedos of the weathering crust are shown in Fig. S4. In addition, we assumed that the differences of albedo, IRF and surface ablation between the control plots and the experimental plots were only contributed by BC, OC and free Fe based on their total light absorption proportions at $550 \mathrm{~nm}$ (Fig. 3b), regardless of ice algae, humic matter and liquid water.

The modelled broadband albedos of the weathering crust in LHG (0.506-0.565) were consistent with the minimum albedos of coarse-grained snow around the cryoconite observed at A13 and A14 (0.56) but were 0.292-0.491 higher than those observed for the LHG cryoconite (0.0510.216) (Fig. 7a) due to the presence of LAIs, thus the cryoconite simultaneously absorbed at least $312.0-486.6 \mathrm{~W} \mathrm{~m}^{-2}$ more than the weathering crust (Fig. 7b). Consequently, the albedo reductions of $\mathrm{BC}, \mathrm{OC}$ and free $\mathrm{Fe}$ (hematite and
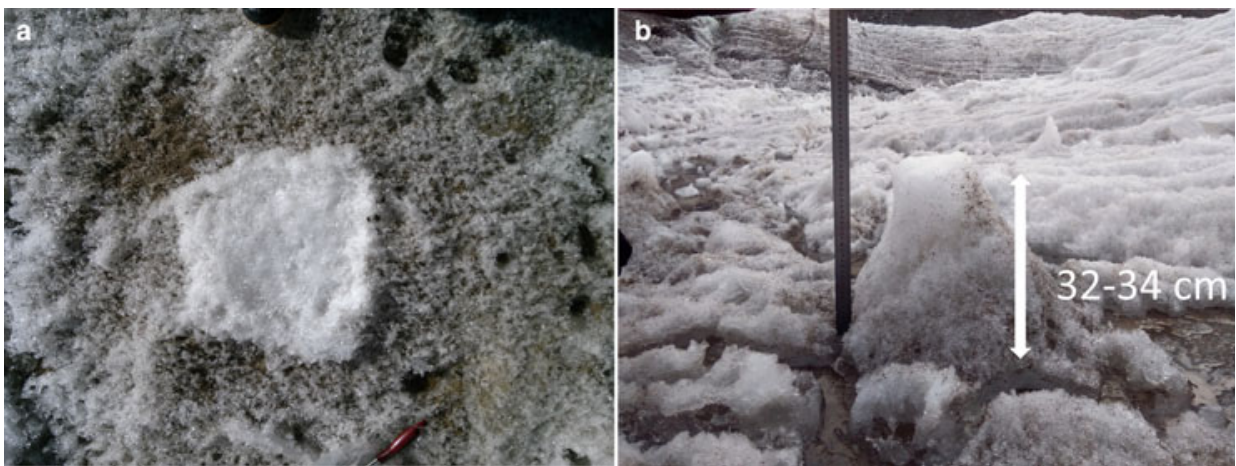

Fig. 6. Observed surface melting enhanced by cryoconite from LHG, Qilian. (a) Weathering crust formed after $\sim 6 \mathrm{~h}$ of melting, and (b) ice pillars that survived after $12 \mathrm{~d}$ of melting. 
Table 3. Heights of ice pillars that survived in the experimental plots and accelerated melting rate caused by cryoconite relative to cryoconite-free ice surfaces from 13 to 25 August 2015

\begin{tabular}{|c|c|c|c|c|c|c|c|}
\hline \multirow[b]{2}{*}{ Site } & \multirow{2}{*}{$\begin{array}{c}\text { Start time } \\
13 \text { Aug } 2015\end{array}$} & \multirow{2}{*}{$\begin{array}{c}\text { End time } \\
25 \text { Aug } 2015\end{array}$} & \multicolumn{2}{|c|}{ Height (cm) } & \multicolumn{2}{|c|}{ Melting rate $\left(\mathrm{cm} \mathrm{d}^{-1}\right)$} & \multirow[b]{2}{*}{ Elevation (m) } \\
\hline & & & Min & Max & Min & Max & \\
\hline A1-1 & $10: 47$ & $18: 40$ & 28 & 32 & 2.27 & 2.60 & 4350 \\
\hline A1-2 & $10: 43$ & $18: 40$ & 30 & 32 & 2.43 & 2.60 & 4349 \\
\hline $\mathrm{A} 2$ & $11: 25$ & $18: 36$ & 34 & 36 & 2.76 & 2.93 & 4375 \\
\hline A3-1 & $12: 21$ & $18: 15$ & 30 & 32 & 2.45 & 2.61 & 4402 \\
\hline A4 & 13:09 & 18:09 & 37 & 40 & 3.03 & 3.28 & 4501 \\
\hline A5 & $13: 37$ & $18: 09$ & 30 & 31 & 2.46 & 2.54 & 4552 \\
\hline A6-1 & $14: 27$ & $17: 22$ & 33 & 35 & 2.72 & 2.89 & 4577 \\
\hline A6-2 & $14: 31$ & $17: 22$ & 34 & 36 & 2.81 & 2.97 & 4577 \\
\hline A7 & $15: 28$ & $10: 37$ & 35 & 38 & 2.97 & 3.22 & 4575 \\
\hline A8-1 & $16: 27$ & $15: 43$ & 28 & 33 & 2.34 & 2.76 & 4598 \\
\hline A8-2 & $16: 53$ & $16: 26$ & 34 & 38 & 2.84 & 3.17 & 4598 \\
\hline
\end{tabular}

goethite) were respectively of $0.159 \pm 0.037,0.108 \pm 0.037$ and $0.154 \pm 0.046$ (Fig. 7a). The associated uncertainties could be due to discrepancies in LAI concentrations and their contributions to total light absorption, solar zenith angle and atmospheric conditions. Furthermore, the averaged IRF of BC was comparable to that of hematite + goethite $\left(\sim 150 \mathrm{~W} \mathrm{~m}^{-2}\right)$ but much higher than that of OC $(102.8 \mathrm{~W}$ $\mathrm{m}^{-2}$ ); the BC IRF in the LHG cryoconite was comparable to or higher than most previously reported BC IRF in the surface snow and ice of Third Pole glaciers (Yang and others, 2015; Ming and others, 2016; Niu and others, 2017a, 2017b; Zhang and others, 2017a, 2017b, 2017c). During the $12 \mathrm{~d}$ in situ experiment, the various LAls in cryoconite effectively enhanced the melting rate by $2.27-3.28$ $\mathrm{cm} \mathrm{d}^{-1}$ compared to a cryoconite-free ice surface under the same meteorological conditions. Free Fe played the most important role in accelerating surface ablation (1.01 \pm $\left.0.25 \mathrm{~cm} \mathrm{~d}^{-1}\right)$, followed by BC and OC $(0.99 \pm 0.15$ and

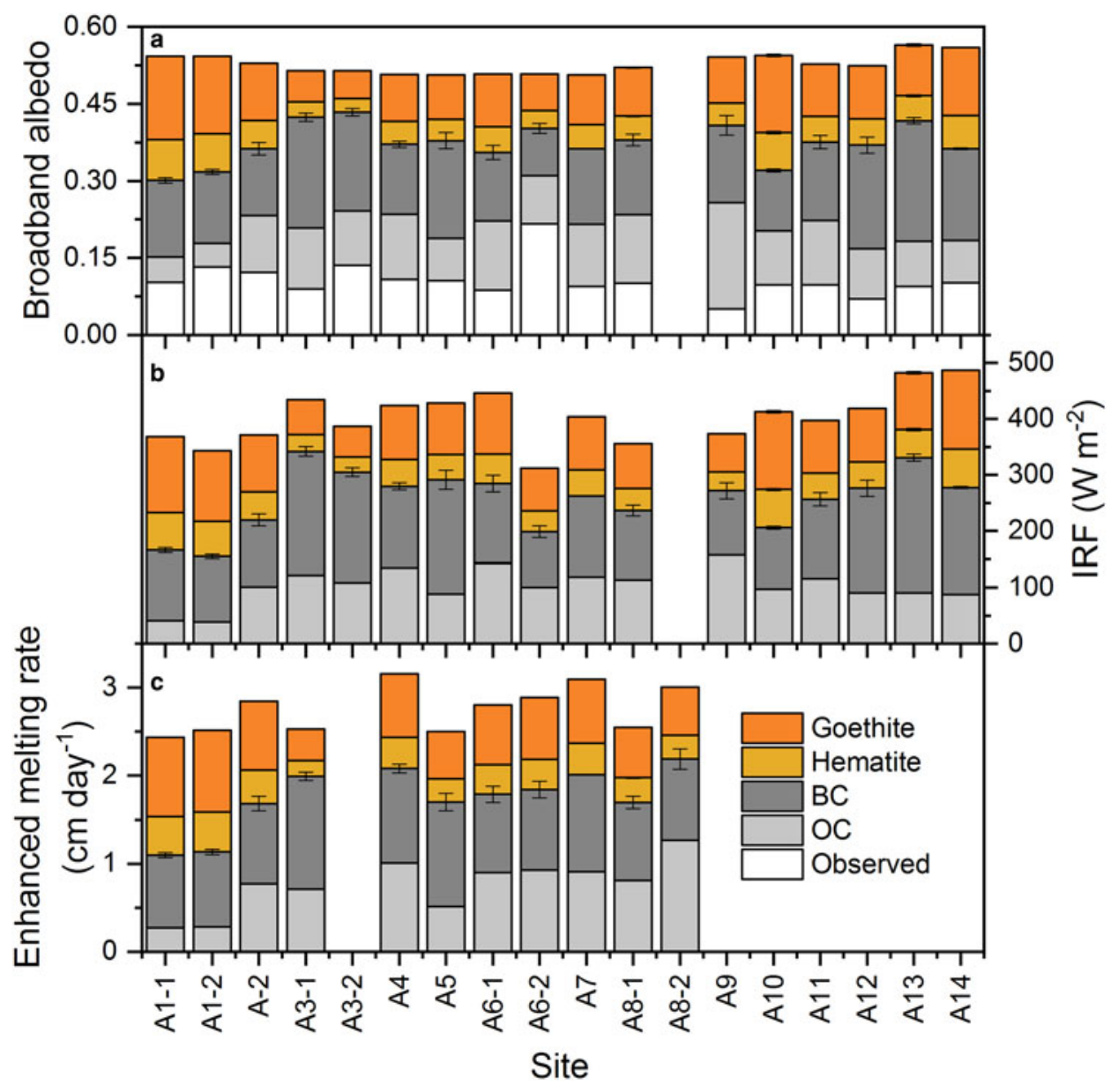

Fig. 7. (a) Simulated broadband albedo of the weathering crust and observed broadband albedo of the LHG cryoconite. The discrepancies are due to the albedo reduction caused by LAIs. Simulated (b) IRF and (c) enhanced melting rate contributed by OC, BC and free Fe (hematite and goethite) in the LHG cryoconite. 
$0.76 \pm 0.30 \mathrm{~cm} \mathrm{~d}^{-1}$, respectively) (Fig. 7c). Considering that the ablation period often lasts for more than 2 months in this area, this melting rate should considerably affect the ablation process of LHG. Therefore, the results highlight that the albedo of cryoconite-loaded ice is critical for the mass balance of Tibetan glaciers.

\section{CONCLUSIONS}

This study presents the particle size distributions, LAI concentrations and spectral albedos of cryoconite and the cryoconite-enhanced melting rates on LHG on the north-eastern Tibetan Plateau. The particle size distribution of LHG cryoconite presented a unimodal pattern. Silt grains $(\sim 2-63 \mu \mathrm{m})$ accounted for $81.9-89.7 \%$ of the total cryoconite particles. The average concentrations of IC, OC and Fe (7.67, 11.18 and $39.94 \mathrm{mg} \mathrm{g}^{-1}$, respectively) were much higher than that of BC $\left(1.28 \mathrm{mg} \mathrm{g}^{-1}\right)$, whereas BC was responsible for a higher fraction of light absorption (38.1\%) than Fe (goethite and hematite) and OC (35.9\% and $26.0 \%$, respectively). Therefore, cryoconite granules containing abundant LAIs can reduce the surface albedo and efficiently absorb solar radiation. Based on spectral albedo observations, cryoconite exhibited the darkest surface and the lowest mean reflectance (i.e., <0.1) across the visible and near-IR wavelength range of any material. Compared with the cryoconite-free ice surface under the same meteorological conditions, cryoconite effectively enhanced the melting rate by $2.27-3.28$ $\mathrm{cm} \mathrm{d}^{-1}$ during the $12 \mathrm{~d}$ in situ experiment. However, free Fe played the most important role in accelerating surface ablation $\left(1.01 \pm 0.25 \mathrm{~cm} \mathrm{~d}^{-1}\right)$, followed by $\mathrm{BC}$ and $\mathrm{OC}$ $\left(0.99 \pm 0.15\right.$ and $0.76 \pm 0.30 \mathrm{~cm} \mathrm{~d}^{-1}$, respectively). The results presented here further enhance our understanding of the complex role of cryoconite in the glacier mass balance in the northern areas of the Tibetan Plateau.

\section{SUPPLEMENTARY MATERIAL}

The supplementary material for this article can be found at https://doi.org/10.1017/jog.2019.41

\section{ACKNOWLEDGEMENTS}

This work was supported by the Chinese Academy of Sciences (XDA20040501, QYZDJ-SSW-DQC039), the National Natural Science Foundation of China (41630754 and 41721091) and the State Key Laboratory of Cryospheric Science (SKLCS-ZZ-2018). The authors gratefully acknowledge the field team for their assistance and the anonymous reviewers and the editor for their helpful comments and suggestions. We are also very grateful to American Journal Experts for editing the English language of this manuscript. Observation data of the spectral albedos and LAI concentrations can be freely shared, contact the corresponding authors for access to the data.

\section{REFERENCES}

Ångström A (1925) The albedo of various surfaces of ground. Geografiska Annaler 7(4), 323-342.

Aoki T and 5 others (2013) Numerical simulation of spectral albedos of glacier surfaces covered with glacial microbes in Northwestern Greenland. AIP Conf. Proc., AIP 176-179. (1).
Aoki T and 6 others (2014) Light-absorbing snow impurity concentrations measured on Northwest Greenland ice sheet in 2011 and 2012. Bull. Glaciol. Res., 32, 21-31

Baccolo G and 5 others (2017) Cryoconite as a temporary sink for anthropogenic species stored in glaciers. Sci. Rep., 7(1), 9623

Bøggild CE, Brandt RE, Brown KJ and Warren SG (2010) The ablation zone in northeast Greenland: ice types, albedos and impurities. J. Glaciol., 56(195), 101-113

Bond TC and Bergstrom RW (2006) Light absorption by carbonaceous particles: an investigative review. Aerosol Sci. Technol., 40(1), 27-67

Bond TC and 5 others (2013) Bounding the role of black carbon in the climate system: a scientific assessment. J. Geophys. Res. Atmos. 118(11), 5380-5552

Chen LWA and 5 others (2015) Multi-wavelength optical measurement to enhance thermal/optical analysis for carbonaceous aerosol. Atmos. Meas. Tech., 8(1), 451-461

Chen J and 5 others (2017) The mass-balance characteristics and sensitivities to climate variables of Laohugou Glacier No. 12, western Qilian Mountains, China. Sci. Cold Arid Regions, 9(6), 543-553

Chow JC and 5 others (2007) The IMPROVE_A temperature protocol for thermal/optical carbon analysis: maintaining consistency with a long-term database. J. Air Waste Manage. Assoc., 57(9), 10141023

Clarke AD and Noone KJ (1985) Soot in the Arctic snowpack - a cause for perturbations in radiative-transfer. Atmos. Environ., 19(12), 2045-2053

Cong $Z$ and 5 others (2013) Historical trends of atmospheric black carbon on Tibetan plateau as reconstructed from a 150-year lake sediment record. Environ. Sci. Technol., 47(6), 25792586

Cong Z and 5 others (2018) Iron oxides in the cryoconite of glaciers on the Tibetan plateau: abundance, speciation and implications. The Cryosphere, 12(10), 3177-3186

Cook J, Edwards A, Takeuchi N and Irvine-Fynn T (2016) Cryoconite: the dark biological secret of the cryosphere. Prog. Phys. Geogr. - Earth Environ., 40(1), 66-111

Cook JM and 5 others (2017) Quantifying bioalbedo: a new physically based model and discussion of empirical methods for characterising biological influence on ice and snow albedo. Cryosphere, 11(6), 2611-2632

Dal Farra A and 5 others (2018) Spectral signatures of submicron scale light-absorbing impurities in snow and ice using hyperspectral microscopy. J. Glaciol., 64(245), 377-386

Di Mauro B and 5 others (2017) Impact of impurities and cryoconite on the optical properties of the Morteratsch Glacier (Swiss Alps). Cryosphere, 11(6), 2393

Doherty SJ, Warren SG, Grenfell TC, Clarke AD and Brandt RE (2010) Light-absorbing impurities in Arctic snow. Atmos. Chem. Phys., 10(23), 11647-11680

Doherty SJ, Dang C, Hegg DA, Zhang RD and Warren SG (2014) Black carbon and other light-absorbing particles in snow of central North America. J. Geophys. Res. Atmos. 119(22), 12807-12831

Dong Z and 5 others (2014a) Physicochemical impacts of dust particles on alpine glacier meltwater at the Laohugou Glacier basin in western Qilian Mountains, China. Sci. Total Environ., 493, 930-942

Dong Z and 5 others (2014b) Physicochemical characteristics and sources of atmospheric dust deposition in snow packs on the glaciers of western Qilian Mountains, China. Tellus Series B - Chem. Phys. Meteorol., 66(1), 20956

Dong Z and 5 others (2016) Provenance of cryoconite deposited on the glaciers of the Tibetan Plateau: new insights from Nd-Sr isotopic composition and size distribution. J. Geophys. Res. Atmos., 121(12), 7371-7382

Du W, Qin X, Liu Y and Wang X (2008) Variation of the Laohugou glacier No. 12 in the Qilian mountains. J. Glaciol. Geocry., 30(3), 373-379 (Chinese in English abstract) 
Feng J, Hu Z, Ju J and Lin Y (2014) The dust provenance and transport mechanism for the Chengdu Clay in the Sichuan Basin, China. Catena, 121, 68-80

Flanner MG, Zender CS, Randerson JT and Rasch PJ (2007) Presentday climate forcing and response from black carbon in snow. J. Geophys. Res. Atmos. 112(D11)

Foreman CM, Sattler B, Mikucki JA, Porazinska DL and Priscu JC (2007) Metabolic activity and diversity of cryoconites in the Taylor Valley, Antarctica. J. Geophys. Res. Biogeosci. 112(G4)

Ganey GQ, Loso MG, Burgess AB and Dial RJ (2017) The role of microbes in snowmelt and radiative forcing on an Alaskan icefield. Nat. Geosci., 10(10), 754

Han $Y$ and 5 others (2007) Evaluation of the thermal/optical reflectance method for discrimination between char- and soot-EC. Chemosphere, 69(4), 569-574

Han $Y$ and 5 others (2011) Comparison of elemental carbon in lake sediments measured by three different methods and 150-year pollution history in Eastern China. Environ. Sci. Technol., 45 (12), 5287-5293

Hansen J and Nazarenko L (2004) Soot climate forcing via snow and ice albedos. Proc. Natl. Acad. Sci. USA, 101(2), 423-428

Hodson A and 5 others (2008) Glacial ecosystems. Ecol. Monogr., 78(1), 41-67

Hodson A and 5 others (2010) The cryoconite ecosystem on the Greenland ice sheet. Ann. Glaciol., 51(56), 123-129

Huang J and 5 others (2011) Dust and black carbon in seasonal snow across Northern China. Bull. Am. Meteorol. Soc., 92(2), 175-181

Irvine-Fynn TD and Edwards A (2014) A frozen asset: the potential of flow cytometry in constraining the glacial biome. Cytometry $A$, 85(1), 3-7

Kaspari S, Skiles SM, Delaney I, Dixon D and Painter TH (2015) Accelerated glacier melt on Snow Dome, Mount Olympus, Washington, USA, due to deposition of black carbon and mineral dust from wildfire. J. Geophys. Res. Atmos., 120(7), 2793-2807

Kirchstetter TW, Novakov T and Hobbs PV (2004) Evidence that the spectral dependence of light absorption by aerosols is affected by organic carbon. J. Geophys. Res. Atmos., 109(D21)

Kohshima S, Seko K and Yoshimura Y (1993) Biotic acceleration of glacier melting in yala glacier, langtang region, Nepal Himalaya. Snow and Glacier Hydrology (Proceeding of the Kathumandu Symposium, November 1992). IAHS Publication, 218, 309-316

Kopacz M and 5 others (2011) Origin and radiative forcing of black carbon transported to the Himalayas and Tibetan Plateau. Atmos. Chem. Phys., 11(6), 2837-2852

Lafon S, Sokolik IN, Rajot JL, Caquineau S and Gaudichet A (2006) Characterization of iron oxides in mineral dust aerosols: implications for light absorption. J. Geophys. Res. Atmos., 111(D21)

Lavanchy VMH, Gaggeler HW, Schotterer U, Schwikowski M and Baltensperger U (1999) Historical record of carbonaceous particle concentrations from a European high-alpine glacier (Colle Gnifetti, Switzerland). J. Geophys. Res. Atmos., 104(D17), 21227-21236

Lekner J and Dorf MC (1988) Why some things are darker when wet. Appl. Opt., 27(7), 1278-1280

Li C and 5 others (2016) Sources of black carbon to the HimalayanTibetan Plateau glaciers. Nat. Commun., 7, 12574

Li X and 5 others (2017) Light-absorbing impurities accelerate glacier melt in the Central Tibetan Plateau. Sci. Total Environ., 587-588, 482-490

Liang Q, Jing H and Gregoire DC (2000) Determination of trace elements in granites by inductively coupled plasma mass spectrometry. Talanta, 51(3), 507-513

Lu Z, Streets DG, Zhang Q and Wang S (2012) A novel back-trajectory analysis of the origin of black carbon transported to the Himalayas and Tibetan Plateau during 1996-2010. Geophys. Res. Lett., 39

Luthi ZL and 5 others (2015) Atmospheric brown clouds reach the Tibetan Plateau by crossing the Himalayas. Atmos. Chem. Phys., 15(11), 6007-6021
MacDonell S and Fitzsimons S (2008) The formation and hydrological significance of cryoconite holes. Prog. Phys. Geogr., 32 (6), 595-610

Mcintyre NF (1984) Cryoconite hole thermodynamics. Can. J. Earth Sci., 21(2), 152-156

Ming J and 5 others (2009) Black Carbon (BC) in the snow of glaciers in west China and its potential effects on albedos. Atmos. Res., 92 (1), 114-123

Ming J, Wang P, Zhao S and Chen P (2013) Disturbance of lightabsorbing aerosols on the albedo in a winter snowpack of Central Tibet. J. Environ. Sci. (China), 25(8), 1601-1607

Ming J, Xiao C, Wang F, Li Z and Li Y (2016) Grey Tienshan Urumqi Glacier No.1 and light-absorbing impurities. Environ. Sci. Pollut. Res., 23(10), 9549-9558

Müller F and Keeler CM (1969) Errors in short-term ablation measurements on melting ice surfaces. J. Glaciol., 8(52), 91-105

Negi HS and Kokhanovsky A (2011) Retrieval of snow albedo and grain size using reflectance measurements in Himalayan basin. Cryosphere, 5(1), 203-217

Niu H and 5 others (2017a) In-situ measurements of lightabsorbing impurities in snow of glacier on Mt. Yulong and implications for radiative forcing estimates. Sci. Total. Environ. 581, 848-856

Niu $\mathrm{H}$ and 5 others (2017b) Distribution of light-absorbing impurities in snow of glacier on Mt. Yulong, southeastern Tibetan Plateau. Atmos. Res. 197, 474-484

Niu $\mathrm{H}$ and 5 others (2018) Seasonal variation and light absorption property of carbonaceous aerosol in a typical glacier region of the southeastern Tibetan Plateau. Atmos. Chem. Phys., 18(9), $6441-6460$

Painter TH and 5 others (2010) Response of Colorado River runoff to dust radiative forcing in snow. Proc. Natl. Acad. Sci. USA, 107 (40): 17125-17130

Pope A and Rees G (2014) Using in situ spectra to explore Landsat classification of glacier surfaces. Int. J. Appl. Earth Obs. Geoinf., 27, 42-52

Qin X and 5 others (2015) Reconstruction of surface air temperature in a glaciated region in the western Qilian Mountains, Tibetan Plateau, 1957-2013 and its variation characteristics. Quat. Int., $371,22-30$

Qu B and 5 others (2014) The decreasing albedo of the Zhadang glacier on western Nyainqentanglha and the role of light-absorbing impurities. Atmos. Chem. Phys., 14(20), 11117-11128

Ramanathan V and Carmichael G (2008) Global and regional climate changes due to black carbon. Nat. Geosci., 1(4), 221-227

Singh SM and 5 others (2013) Atmospheric deposition studies of heavy metals in Arctic by comparative analysis of lichens and cryoconite. Environ. Monit. Assess., 185(2), 1367-1376

Singh SM and 5 others (2017) Elemental variations in glacier cryoconites of Indian Himalaya and Spitsbergen, Arctic. Geosci. Front., 8(6), 1339-1347

Sokolik IN and Toon OB (1999) Incorporation of mineralogical composition into models of the radiative properties of mineral aerosol from UV to IR wavelengths. J. Geophys. Res. Atmos., 104(D8), 9423-9444

Stibal M, Sabacka M and Kastovska K (2006) Microbial communities on glacier surfaces in Svalbard: impact of physical and chemical properties on abundance and structure of cyanobacteria and algae. Microb. Ecol., 52(4), 644-654

Stibal M, Sabacka M and Zarsky J (2012) Biological processes on glacier and ice sheet surfaces. Nat. Geosci., 5(11), 771-774

Takeuchi N and Li ZQ (2008) Characteristics of surface dust on Urumqi Glacier No. 1 in the Tien Shan Mountains, China. Arct. Antarct. Alp. Res., 40(4), 744-750

Takeuchi N, Kohshima S, Goto-Azuma K and Koerner RM (2001a) Biological characteristics of dark colored material (cryoconite) on Canadian Arctic glaciers (Devon and Penny ice caps). Memoirs Natl. Inst. Polar Res. Special issue, 54, 495-505 
Takeuchi N, Kohshima S and Seko K (2001b) Structure, formation, and darkening process of albedo-reducing material (cryoconite) on a Himalayan glacier: a granular algal mat growing on the glacier. Arct. Antarct. Alp. Res., 33(2), 115-122

Takeuchi N, Matsuda Y, Sakai A and Fujita K (2005) A large amount of biogenic surface dust (cryoconite) on a glacier in the Qilian Mountains, China. Bull. Glaciol. Res., 22, 1-8

Takeuchi N, Uetake J, Fujita K, Aizen VB and Nikitin SD (2006) A snow algal community on Akkem glacier in the Russian Altai mountains. Ann. Glaciol., 43(1), 378-384

Takeuchi N, Nagatsuka N, Uetake J and Shimada R (2014) Spatial variations in impurities (cryoconite) on glaciers in northwest Greenland. Bull. Glaciol. Res., 32, 85-94

Takeuchi $N$ and 5 others (2015) The effect of impurities on the surface melt of a glacier in the Suntar-Khayata Mountain Range, Russian Siberia. Front. Earth Sci., 3, 82

Tegen I and 5 others (1997) Contribution of different aerosol species to the global aerosol extinction optical thickness: estimates from model results. J. Geophys. Res. Atmos., 102(D20), 23895-23915

Wang S, Tedesco M, Xu M and Alexander PM (2018) Mapping ice algal blooms in southwest Greenland from space. Geophys. Res. Lett., 45(21), 11,779-11,788

Warren SG and Brandt RE (2008) Optical constants of ice from the ultraviolet to the microwave: a revised compilation. J. Geophys. Res. Atmos., 113(D14)

Warren SG and Wiscombe WJ (1980) A model for the spectral albedo of snow. II: Snow containing atmospheric aerosols. J. Atmos. Sci., 37(12), 2734-2745

Wei T, Dong Z, Kang S, Qin X and Guo Z (2017) Geochemical evidence for sources of surface dust deposited on the Laohugou glacier, Qilian Mountains. Appl. Geochem., 79, 1-8

Williamson $C$ and 5 others (2018) Ice algal bloom development on the surface of the Greenland Ice Sheet. FEMS Microbiol. Ecol., 94 (3), fiy025

Wiscombe WJ and Warren SG (1980) A model for the spectral albedo of snow. I: Pure snow. J. Atmos. Sci., 37(12), 2712-2733

Wu G, Xu T, Zhang X, Zhang C and Yan N (2016) The visible spectroscopy of iron oxide minerals in dust particles from ice cores on the Tibetan Plateau. Tellus Series B - Chem. Phys. Meteorol., 68 (1), 29191

$\mathrm{Xu} \mathrm{J}$ and 6 others (2013) Seasonal and diurnal variations in aerosol concentrations at a high-altitude site on the northern boundary of Qinghai-Xizang Plateau. Atmos. Res., 120, 240-248

Yallop ML and 6 others (2012) Photophysiology and albedo-changing potential of the ice algal community on the surface of the Greenland ice sheet. ISME J., 6(12), 2302

Yang S, Xu B, Cao J, Zender CS and Wang M (2015) Climate effect of black carbon aerosol in a Tibetan Plateau glacier. Atmos. Environ., 111, 71-78

Zhang X and 6 others (2003) Characterization of soil dust aerosol in China and its transport and distribution during 2001 ACE-Asia: 1. Network observations. J. Geophys. Res. Atmos., 108(D9)

Zhang Y, Liu S, Shangguan D, Li J and Zhao J (2012) Thinning and shrinkage of Laohugou No. 12 glacier in the Western Qilian Mountains, China, from 1957 to 2007. J. Mt. Sci., 9(3), 343-350

Zhang M, Qin X, Du W, Liu Y and Sun W (2013) Glacier change in the Laohugou river basin monitored by remote sensing from 1957 to 2009. J. Arid. Land Resour. Environ., 4, 011 (Chinese in English abstract)

Zhang X, Wu G, Zhang C, Xu T and Zhou Q (2015) What is the real role of iron oxides in the optical properties of dust aerosols? Atmos. Chem. Phys., 15(21), 12159-12177

Zhang Z, Dong Z, Li J, Qian G and Jiang C (2016) Implications of surface properties for dust emission from gravel deserts (gobis) in the Hexi Corridor. Geoderma, 268, 69-77

Zhang Y and 6 others (2017a) Light-absorbing impurities enhance glacier albedo reduction in the southeastern Tibetan plateau. J. Geophys. Res. Atmos., 122(13), 6915-6933

Zhang $Y$ and 6 others (2017b) Light-absorbing impurities on Keqikaer Glacier in western Tien Shan: concentrations and potential impact on albedo reduction. Sci. Cold Arid Regions, 9 (2), 97-111

Zhang $Y$ and 6 others (2017c) Characteristics of black carbon in snow from Laohugou No. 12 glacier on the northern Tibetan Plateau. Sci. Total. Environ., 607, 1237-1249 